\title{
EL PRINCIPIO DE IGUALDAD DE ARMAS: UN ANÁLISIS CONCEPTUAL
}

Simón Moratto*

Resumen: El principio de igualdad de armas es un mandato esencial que consiste en que "cada parte debe tener una oportunidad razonable para presentar su caso en condiciones que no la pongan en desventaja con respecto a su oponente"1. Esta figura, a pesar de su connotada y evidente importancia, no ha sido objeto de estudio profundo y serio en la doctrina y la jurisprudencia colombianas. Lo anterior ha permitido un uso irresponsable y equivocado de este concepto, y es de ahí que nace la necesidad de este artículo, el cual tiene por objeto, sin pretender ser exhaustivo, dar una mayor claridad sobre este mandato de optimización, empezando por revisar sus antecedentes; pasando por el análisis de cada uno de sus elementos esenciales; la referencia a algunas categorías desarrolladas en la jurisdicción internacional que son de suma importancia para alcanzar un entendimiento íntegro de dicho principio; el señalamiento de las diferentes posiciones sobre su fundamento, definición y alcance; y una diferenciación con otros derechos y principios con los que suele confundirse.

* Abogado por la Universidad Externado de Colombia y magíster en Derecho Penal por la Universidad de Salamanca (España). Correo-e: simonmoratto@gmail.com. Fecha de recepción: 20 de mayo de 2020. Fecha de aceptación: 12 de enero de 2021. Para citar el artículo: Simón MoratTo. "El principio de igualdad de armas: un análisis conceptual”, Revista Derecho Penal y Criminología, vol. 41, n. ${ }^{\circ} 110$, enero-junio de 2020, Bogotá, Universidad Externado de Colombia, pp. 177-202. DOI: https:// doi.org/10.18601/01210483.v41n110.08.

1 Tribunal Europeo de Derechos Humanos. Bulut v. Austria, App, n. ${ }^{\circ}$ 17358/90, 22 de febrero de 1996, par. 47. 
De esta manera, se sentarán las bases para que, posteriormente, sea posible abrir un debate organizado acerca de esta figura que haga viable un ejercicio optimizado y responsable de ella.

Palabras clave: principio; igualdad; armas; desventaja; adversarial.

\title{
THE EQUAL ARMS PRINCIPLE: A CONCEPTUAL ANALYSIS
}

\begin{abstract}
The principle of equality of arms is an essential optimization requirement, which requires that "each party must be afforded a reasonable opportunity to present his case under conditions that do not place him at a disadvantage vis-à-vis his opponent". This procedural figure, notwithstanding, has not been studied deeply and seriously in Colombian doctrine and jurisprudence despite its evident importance. The aforementioned situation has allowed an irresponsible and mistaken use of this concept and that is the reason why this article arises, which aims, without pretending to be exhaustive, to give a greater clarity about this optimization requirement, starting with a study about its antecedents, going through the analysis of its essential features, the reference to different positions about its basis, definition, content and scope, its differentiation with other rights and principles and the reference to some categories developed at the international jurisdiction that are relevant to achieve a full understanding of it. Subsequently, it will be possible to open an organized debate on this procedural figure in order to make viable an optimized and responsible use of this concept.
\end{abstract}

Keywords: principle; equality; arms; disadvantage; adversarial.

\section{ANTECEDENTES DEL PRINCIPIO DE IGUALDAD DE ARMAS}

El principio de igualdad de armas rige hoy derechos procesales que ya se reconocían en la antigua Grecia. La máxima audi alteram partem era considerada un medio esencial para la toma de una decisión de calidad y un precepto de justicia. Demóstenes, por ejemplo, hacía referencia a que tanto fiscal como acusado debían ser igualmente escuchados antes de que se emitiera la decisión ${ }^{2}$.

Así mismo, en materia probatoria, el derecho en Atenas consagraba ciertas prerrogativas, verbigracia, la posibilidad del acusado de extraer material probatorio de los interrogatorios, hearsay evidence era inadmisible por regla general; se admitía

2 Omkar Sidhu. The concept of equality of arms in criminal proceedings under article 6 of the European Convention of Human Rights. Cambridge, Intersentia, 2011, p. 13. 
la tortura como un instrumento para llegar a la verdad ${ }^{3}$ y era viable la representación del acusado mediante oradores profesionales ${ }^{4}$.

Posteriormente, en Roma, se continuó con la línea trabajada en Atenas y el Digesto de Justiniano prescribía que un padre no podía matar a su hijo sin antes haberle otorgado la posibilidad de ser escuchado ${ }^{5}$. De la misma manera, Tácito señalaba que no importaba qué tan odioso o culpable pudiera ser un acusado, era obligatorio escucharle de acuerdo con el precedente ${ }^{6}$. Así mismo, se procuraba en alguna medida la imparcialidad del juez, de ahí que en la Ley de las XII Tablas se estipulara que un juez incurría en pena capital si aceptaba sobornos a cambio de su decisión?

Bajo la misma lógica, el Codex Iustinianus indicaba que una vez imputados los cargos no se podía condenar en ausencia y en caso de duda se prefería la interpretación más favorable al sospechoso ${ }^{8}$. Es de resaltar que en este cuerpo normativo el acusado podía ser representado por abogados, los cuales, para esa época, habían adquirido ya un estatus profesional ${ }^{9}$.

Más adelante, en la Europa Occidental, entre los siglos IX y XIII, llegarían los juicios por juramento, ordalía y combate. En este periodo se presentó una regresión en materia de garantías procesales y se apelaba a la divinidad para el alcance de correctos resultados en el procedimiento. En ese contexto se declaraba culpable al acusado dependiendo de su buena reputación y de si su juramento había sido tomado correctamente; si ambas condiciones concurrían positivamente, se procedía a su absolución, de lo contrario se daba paso a la ordalía. Ahora bien: en casos de crímenes odiosos o subrepticios los sospechosos podían confrontar a los acusadores en batalla, donde las reglas exigían que cada uno debía estar dotado con las mismas armas y armaduras, y es esta ya una temprana expresión del principio de igualdad de armas. Finalmente, el juicio por combate para el siglo XV devino casi obsoleto ${ }^{10}$.

Desde otra perspectiva, es importante destacar que las cortes eclesiásticas europeas para 1198 habían implementado el procedimiento inquisitivo, originalmente instituido

3 Omkar Sidhu. Op. cit., p. 15.

4 Ibídem.

5 Alan Watson (ed.) (tr.). The Digest of Justinian, vol. 4. Pennsylvania, University of Pennsylvania Press, 1998, p. 333.

6 Omkar Sidhu. Op. cit., p. 16.

7 Frank Card Bourne y Paul Robinson Coleman-Norton. Ancient Roman Statutes: a translation with introduction, commentary, glossary and index. Texas, Clyde Pharr, 1961, p. 12.

8 Alan Watson. Op. cit., pp. 474, 480 y 482.

9 Omkar Sidhu. Op. cit., p. 18.

10 Robert Bartlett. Trial by fire and water: The medieval judicial ordeal. Oxford, Clarendon, 1986, pp. 116-118, 120, 122-123. 
por el papa Inocencio III, en el que los jueces podían investigar de oficio, recolectar fuentes de prueba y perseguir sospechosos. Algunas garantías de los perseguidos se reconocían en ese contexto, como era el caso de la facultad de ser notificado y contar con tiempo suficiente para examinar los cargos, se autorizaba la asistencia legal ${ }^{11}$, llamar y solicitar un nuevo examen de los testigos, entre otros. Empero, cabe recordar que seguía siendo un procedimiento principalmente carente de salvaguardas procesales donde la tortura desempeñó un papel central, especialmente en las inquisiciones de herejía en las que las oportunidades para la defensa fueron muy limitadas, verbigracia, los acusados no eran confrontados con los testigos en su contra ni sabían sus identidades ya que se pretendía proteger la vida de los informantes, aunque es rescatable que los acusados, para evitar falsos testimonios, podían señalar que los declarantes eran enemigos mortales y la declaración asociada a ellos se retiraba ${ }^{12}$ (salvo para probar esta enemistad, los acusados no podían llamar testigos en su defensa).

El procedimiento antemencionado finalmente devino inactivo en el siglo XVI, pero tuvo una fuerte influencia en la Ordenanza Penal francesa de 1670, que introdujo en Francia un conocimiento preciso y comprensivo sobre el proceso inquisitivo, el cual constaba de una fase previa al juicio donde los jueces conducían la investigación para establecer el delito cometido y reunir material probatorio. En cuanto a los derechos de los procesados, debe decirse que tenían acceso a un intérprete, a un abogado (salvo si se trataba de casos capitales) ${ }^{13}$ que sólo después del interrogatorio podía ser consultado por el sospechoso. Además, se podían hacer explicaciones frente a la prueba en contra. Posteriormente se llegaba a la acusación, donde se escuchaban las declaraciones finales de los testigos, quienes eran confrontados por el acusado, el cual estaba facultado para objetar su inclusión en el proceso y, en general, estaba habilitado para reaccionar frente a todo medio de prueba actual. Conviene resaltar que sólo hasta este momento adquiría plena consciencia de la naturaleza de los cargos que se le atribuían ${ }^{14}$. De manera subsiguiente, se llevaba a cabo una revisión de la prueba por parte de una asamblea de jueces, y en esta fase, frente a los testigos, los acusados no podían extraer de ellos prueba que no hubiera sido ya obtenida por interrogatorio judicial ${ }^{15}$. De la misma manera, los fiscales no podían interrogar testigos de la defensa o estar presentes en la examinación de estos. A posteriori, se dictaba una decisión definitiva o interlocutoria mediante el voto de los jueces. Finalmente debe señalarse que aunque la confesión seguía siendo la prueba reina, la tortura para llegar a ella fue limitada pues únicamente procedía en casos capitales,

11 Adhémar Esmein. A history of continental criminal procedure. New Jersey, 2000, pp. 90-91.

12 Henry Charles Lea. A history of the inquisition of the middle ages. New York, Harper and Brothers, Franklin Square, 1887, pp. 430-440

13 Adhémar Esmein. Op. cit., p. 227.

14 Adhémar Esmein. Op. cit., p. 230.

15 Richard Andrews. Law, Magistracy and crime in old regime Paris 1735-1789, vol. 1: The system of criminal justice. Cambridge, Cambridge University Press, 1994, pp. 434-435. 
debía ser autorizada por la Corte de Apelación y si no se proveía completamente o había retractación, el procesado no podía enfrentar la pena de muerte. Igualmente, se exigía que la confesión fuera coherente con los demás medios de prueba y si mediante la tortura se encontraba nueva evidencia en un determinado ámbito, no podía el acusado volver a ser torturado por ese mismo asunto ${ }^{16}$.

Contrario al desarrollo francés, en Inglaterra no se compartió la idea del método inquisitivo como un instrumento idóneo para asegurar convenientes resultados procesales; en su lugar, los juicios por jurado evolucionaron en el sistema acusatorio.

El origen de los jurados se remonta al siglo XII, aunque sólo en el siglo XIV alcanzaron una fuerte penetración. Los jurados penales se dividían en dos: acusador o gran jurado y juzgador o pequeño jurado. Los primeros (cuya primera función en justicia penal fue atribuida en 1166) determinaban si una persona era sospechosa por haber cometido una ofensa, decisión a la que llegaban teniendo en cuenta su propio conocimiento o información allegada por otros (para los años 1700 basarían su respuesta únicamente en los medios de prueba proveídos por el fiscal). Ulteriormente, por considerárseles inefectivos para llevar a cabo las investigaciones ${ }^{17}$, en el siglo XIX la policía asumió las labores de investigación, desplazando a los jueces de paz, que habían tomado esa carga después de que los jurados cesaron en esa función. Es así como los jueces asumieron una labor eminentemente judicial y determinaban si el caso debía ir a juicio o no. En esa tarea de examen magisterial hay algunas características asociadas con justicia procesal, verbigracia, por regla general, el examen se realizaba en presencia del acusado y de manera pública, contaba con el derecho a guardar silencio y tenía la posibilidad de llamar testigos e interrogar a los de la fiscalía.

En la fase subsiguiente, para el siglo XIV, el acusado podía objetar la presencia de jueces en el juicio si estos habían participado en la etapa previa con el objetivo de asegurar imparcialidad en el proceso ${ }^{18}$. Aquí, el pequeño jurado emitía veredicto basándose únicamente en su propio conocimiento e investigaciones en lugar de apoyarse en evidencia y testigos, aunque para 1555 se admitieron estos últimos en favor de la fiscalía y cuyas declaraciones podía presenciar el procesado (los testigos de la defensa sólo se admitieron hasta los años 1600). Estas reglas fueron cambiando y en el siglo XIX los jurados debían fundamentar su decisión en los medios de prueba presentados ante la Corte, el sospechoso contaba con la opción de hacerse testigo en su propia causa y le era factible acudir a representación legal ${ }^{19}$. Finalmente, es de destacar que la presunción de inocencia ya era exigible.

16 Adhémar Esmein. Op. cit., p. 234.

17 William Blackstone. Commentaries on the law of England, 13. . ed. London, 1800, pp. 302-303.

18 Omkar Sidhu. Op. cit., p. 31.

19 Omkar Sidhu. Op. cit., p. 36. 
Los juicios por jurado ingleses fueron un modelo de inspiración para la reforma del proceso penal en Francia, que se tradujo en el Código de Procedimiento Penal francés de 1808 y cuya relevancia es resaltable en la medida en que influyó un sinnúmero de sistemas procesales alrededor del mundo. Como aspectos negativos en el ámbito de las garantías en el proceso pueden mencionarse los siguientes: en la etapa preliminar de examen para determinar si había un caso que ameritara investigarse, el magistrado estaba facultado para llamar testigos secretamente y escucharlos sin la presencia del acusado, quien era también interrogado en secreto y no tenía derecho a ser informado de los cargos o a ver declaraciones de testigos o cualquier otra prueba (a menos que discrecionalmente así lo decidiera el juzgador), tampoco podía llamar testigos ni controvertir los expertos llamados por la Corte ${ }^{20}$. Contrario sensu, algunos aspectos positivos fueron: la facultad del acusado para acceder a un abogado y a comunicarse libremente con él, quien además podía familiarizarse con el caso y los documentos antes del interrogatorio. Una vez se determinaba por la Cámara de Acusación que había lugar a juicio, el procesado tenía completo conocimiento de los cargos y la causa de la acusación y así, dentro de las veinticuatro horas siguientes a la determinación de la necesidad del juicio, se le trasladaba al Palacio de Justicia donde le era notificado su derecho a controvertir la validez de los procedimientos ante la Corte de Casación ${ }^{21}$. Si el sospechoso no tenía representante la Corte le asignaba un abogado, había descubrimiento probatorio y podía acceder a todos los documentos, reportes oficiales y declaraciones ${ }^{22}$ y antes del juicio se le informaba de la lista de testigos que iban a comparecer. Además, se contaba con reglas apropiadas para la defensa en el juicio, el cual era llevado a cabo en público, tenía carácter oral ${ }^{23}$ y allí le era posible a la defensa citar testigos.

Por otra parte, conviene resaltar los avances que en el orden constitucional se han originado en la medida en que han conferido un valor añadido a los derechos del acusado y contribuyen en la percepción de buen gobierno pues refleja el sometimiento del Estado al derecho. Así, por ejemplo, se encuentra la Carta Magna de Inglaterra de 1215, declaración de garantías de ciertos derechos y libertades de sujetos libres del Reino que fue concebida como ley fundamental y superior a la ley estatutaria, cuyo capítulo 29 es considerado expresión germinal del due process of law.

En ese orden de ideas, es sustancialmente significativo, por su influencia en el constitucionalismo de Occidente, su contribución en la formación de la tradición legal angloamericana y su incidencia en el marco de la Declaración Universal de los Derechos Humanos y el Pacto Internacional de Derechos Civiles y Políticos, el Bill of Rights de 1791, que consagra la cláusula del debido proceso, la prohibición de

20 Adhémar Esmein. Op. cit., pp. 505-506.

21 Adhémar Esmein. Op. cit., p. 511.

22 Ibídem.

23 Adhémar Esmein. Op. cit., pp. 510-515, 534-535. 
double jeopardy y el derecho a la no autoincriminación, a un juicio público y expedito, a un jurado imparcial, a ser informado de la naturaleza y causa de los cargos, a controvertir testigos en contra, a llamar testigos en favor y a tener representación jurídica.

En esa línea, los franceses también hicieron desarrollos destacables que inspiraron similares declaraciones de derechos en la mayoría de las constituciones de otros estados europeos en el siglo XIX, además de ser un antecedente trascendental del Convenio Europeo de Derechos Humanos. Este instrumento fue la Declaración de los Derechos del Hombre y del Ciudadano de 1789, que contiene en su artículo 7. ${ }^{\circ}$ la cláusula del debido proceso y en el artículo $9 .^{\circ}$ se ocupa de la presunción de inocencia.

Para concluir, es obligatoria la referencia al salto que dio toda esta evolución en materia de derechos del procesado al ámbito internacional luego de la Segunda Guerra Mundial, cuando los estados empezaron a preocuparse por la efectiva protección de los derechos humanos en un mundo cada vez más globalizado.

Antes de que el derecho a un juicio justo se consagrara en la mayoría de instrumentos internacionales sobre derechos humanos, ya existían algunas preocupaciones con el objetivo de asegurar justicia al acusado en el derecho internacional. Es así como el marco procesal de los juicios llevados a cabo ante el Tribunal Militar Internacional de Núremberg entre 1946 y 1949, influido por la tradición adversarial angloamericana, consagraba: el derecho a guardar silencio durante el interrogatorio; al menos treinta días antes del juzgamiento el acusado tenía derecho a una copia de la acusación en lenguaje para él comprensible; el juicio era público y conducido en un idioma que pudiera entender; el sospechoso tenía derecho a estar presente en el proceso y a ser presumido inocente; contaba además con la facultad de defenderse a sí mismo o mediante abogado designado por él o asignado por el tribunal. Del mismo modo, le era permitido interrogar a los testigos de la fiscalía y solicitarle al juez procurar testigos en su defensa, conservaba la opción de ejercer una declaración final antes de que el tribunal emitiera juicio y la decisión final del juzgador debía ser razonada, aunque no estaba abierta a apelación.

Después de los juicios de Núremberg, la finalidad de lograr justicia procesal también se persiguió mediante la elaboración de la Declaración Universal de los Derechos Humanos y el Pacto Internacional de Derechos Civiles y Políticos, instrumentos que pretendían asegurar un orden político internacional y promover la protección de los derechos humanos. El primero en sus artículos $10 .^{\circ}$ y $11 .^{\circ}$ enmarca el derecho a un juicio justo y establece los derechos del acusado a la presunción de inocencia, igualdad en el juicio, a una audiencia pública ante tribunal independiente e imparcial y a todas las garantías necesarias para la defensa. Más específico es el segundo, cuyo artículo $14{ }^{\circ}$ reconoce al acusado el derecho de igualdad ante las cortes, a un juicio público y justo, a un tribunal independiente e imparcial, a un proceso sin dilaciones injustificadas, a ser presumido inocente, a ser informado de los cargos, al adecuado tiempo y facilidades para la preparación de la defensa, a estar presente en el juicio, 
a representarse a sí mismo o mediante abogado, a interrogar y llamar testigos, a un intérprete, a guardar silencio, a no autoincriminarse y prescribe también el derecho a indemnización por errónea condena.

Los dos anteriores instrumentos fueron modelos de inspiración para la adopción del artículo 6. ${ }^{\circ}$ del Convenio Europeo de Derechos Humanos, conocido como el pacto que estableció el más desarrollado y efectivo régimen legal internacional para la protección de este tipo de prerrogativas, cuya relevancia ha sido tal que sirvió de referencia para la elaboración de otros modelos regionales de tratados de derechos humanos ${ }^{24}$. La jurisprudencia del Tribunal de Estrasburgo ha influido en cientos de decisiones judiciales y muchas constituciones han escrito sus catálogos de derechos fundamentales con base el texto de este convenio. Concretamente ese artículo $6 .^{\circ}$, que consagra el derecho a un juicio justo, ha permitido el mayor avance que en el campo jurisprudencial se ha originado con respecto al principio de igualdad de armas.

\section{DISECCIÓN DEL CONCEPTO}

Con el objetivo de lograr un panorama claro y comprensivo del principio de igualdad de armas como un todo, es conveniente esclarecer cada uno de sus elementos fundamentales de manera que, entendiéndolos por separado y de manera detallada, pueda darse posteriormente una lectura íntegra y coherente de él.

\subsection{Concepto de "principio"}

La definición de "principio" y sus diferencias con respecto a las reglas ha sido un tema ampliamente debatido en la filosofía del derecho ${ }^{25}$. Entrar en detalle en las discusiones sobre este tema excede los propósitos de este texto, por lo que este trabajo se limita a señalar los aspectos más relevantes que en este tópico han sido desarrollados por Robert Alexy ${ }^{26}$.

El debate inicialmente se dio con la crítica que hace Dworkin a la tesis expuesta por H. L. Hart en virtud de la cual, cuando no existe regla aplicable o, cuando existiendo, es indeterminada, el juez debe decidir discrecionalmente. Lo que señala Dworkin es que el ordenamiento jurídico está conformado por reglas y principios y así, cuando un juez no encuentra una regla para el caso concreto, debe aplicar los principios y no actuar absolutamente de manera discrecional ${ }^{27}$.

24 Omkar Sidhu. Op. cit., p. 62.

25 Robert Alexy. Teoría de los derechos fundamentales. Madrid, Centro de Estudios Constitucionales, 1997, p. 64; Carlos Bernal Pulido. El Principio de proporcionalidad y los derechos fundamentales. Madrid, Centro de Estudios Políticos y Constitucionales, 2003, p. 569.

26 Ibídem.

27 Ronald Dworkin. Los Derechos en serio, 2. ${ }^{a}$ ed. Barcelona, Ariel, 1989, pp. 102-145. 
Para este último autor, si bien reglas y principios tienen en común que regulan conductas y se utilizan para fundamentar decisiones jurisdiccionales, se diferencian en que las primeras se aplican por completo o no se aplican en un caso determinado, es decir, si se dan los supuestos de hecho consagrados se hace uso de ellas, pero, si por el contrario, los hechos previstos no concurren, o convergen pero al unísono opera una circunstancia prevista como excepción, no hay lugar a su aplicación ${ }^{28}$. Los principios, por su parte, no señalan exactamente cuáles son los supuestos de hecho en los que deben aplicarse ni sus consecuencias jurídicas. Un principio es "una razón a favor de argumentaciones encaminadas en cierto sentido, pero no implica necesariamente una decisión concreta" 29 . Una segunda diferencia radica en que los principios gozan de la "dimensión de peso específico o importancia" ${ }^{30}$ y con base en ella el juzgador decide aquellos casos donde se advierte la pugna entre principios. En este contexto, el mayor peso atribuido a uno de ellos determina el fallo para ese caso concreto, siendo posible que, en otras circunstancias, la misma disputa genere una decisión completamente opuesta. Las reglas, en cambio, no gozan de esta dimensión; como se decía, una regla se aplica o no se aplica, y en caso de tensión entre reglas, el juez no entra a ponderar, sino que establecerá la invalidez de una u otra con base en los criterios de jerarquía, temporalidad o especialidad.

Ante esa distinción hecha por Dworkin, Alexy critica el primer criterio señalado en el entendido de que esa formulación (o todo o nada) implicaría el conocimiento de todas las excepciones a las reglas (lo cual es imposible pues en cada caso concreto pueden aparecer nuevas excepciones que deban ser aplicadas), de lo contrario no sería posible formular una regla ni extraer con seguridad las consecuencias jurídicas previstas ${ }^{31}$. Aun siendo realizable, sería igualmente factible conocer todas las excepciones que pueden tener los principios, caso en el que una diferenciación entre reglas y estos últimos devendría insulsa.

No obstante lo anteriormente señalado, Alexy acoge el segundo criterio y va más allá, estableciendo que las reglas son normas (categoría genérica dentro de la cual se encuentran también los principios) que "contienen determinaciones en el ámbito de lo fáctica y jurídicamente posible" y que pueden o no cumplirse (donde si se dan los supuestos de hecho, procede la subsunción, y de no ser así, no se ejecuta la consecuencia jurídica (sólo de esta manera puede entenderse el todo o nada de Dworkin) ${ }^{32}$, mientras que los principios son “mandatos de optimización”, los cuales

28 Ronald Dworkin. The model of Rules, en The University of Chicago Law Review, vol. 35, Chicago, University of Chicago Law School, 1967, pp. 14-46, disponible en [https://chicagounbound uchicago. edu/cgi/viewcontent.cgi?article=3553\&context=uclrev] (consulta: 7 de julio de 2019).

29 Ibídem.

30 Ibídem.

31 Ibídem.

32 Ibídem. 
"ordenan que algo sea realizado en la mayor medida posible, dentro de las posibilidades jurídicas y reales existentes" 33 , es decir, pueden cumplirse en diferente grado. Por otro lado, la forma jurídica mediante la cual se aplican las reglas es la subsunción y los conflictos entre ellas se solucionan con los criterios de especialidad, jerarquía, temporalidad o mediante el establecimiento de cláusulas de excepción, mientras que en caso de colisiones entre principios, uno de ellos tiene que ceder frente al otro en esas circunstancias específicas del caso concreto, lo cual se determina a través de un proceso de ponderación del que surge una regla que establece la precedencia de uno con respecto al otro. De esta manera, principios y reglas se diferencian cualitativamente, por la forma en que se aplican y la manera en la que se resuelven los conflictos entre ellos, y no con base en un simple criterio cuantitativo o de grado.

Como consecuencia de lo anterior, establecer el contenido exacto de un principio no resulta pragmático. Debido a su naturaleza, debe reconocerse que, a pesar de que su diferencia fundamental con las reglas es una cuestión cualitativa y no cuantitativa, tienen un contenido abstracto que los hace normas abiertas, cuyo significado y aplicación requerirá muchas veces de las circunstancias de los casos sub judice. Esta consideración es importante en el caso del principio de igualdad de armas, pues establece una característica relevante que servirá para la comprensión de su esencia y alcance específico en el marco de un procedimiento penal donde, si bien este mandato no prescribe un catálogo preciso de derechos, sí busca que ciertas garantías sean aplicadas justamente ${ }^{34}$, dadas las posibilidades jurídicas y fácticas existentes, aunque nada obsta para que bajo su filosofía, prerrogativas que no han sido previstas puedan ser reconocidas con el objetivo optimizar esa paridad entre las partes.

\subsection{Concepto de "igualdad"}

Como regla general, el derecho a la igualdad ordena que todos los ciudadanos estén sometidos a un mismo cuerpo normativo y a un mismo sistema jurídico ${ }^{35}$. El Estado tiene la obligación de tratar de manera igualitaria a todas aquellas personas que se encuentran en una misma situación. Ahora bien: al lado de esta concepción formal de igualdad se encuentra su acepción en sentido material ${ }^{36}$, según la cual deberá darse un tratamiento diferenciado a aquellos que se encuentran en diferentes posiciones,

33 Robert Alexy. Op. cit., p. 86.

34 Masha Fedorova. The Principle of Equality of Arms in International Criminal Proceedings. Cambridge, Intersentia, 2012, p. 10.

35 Jaime Bernal Cuéllar y Eduardo Montealegre Lynett. El proceso penal, tomo I: Fundamentos constitucionales y teoría general, 6. ${ }^{a}$ ed. Bogotá, Universidad Externado de Colombia, 2013, p. 92.

36 Corte Constitucional de Colombia. Sentencia T-036 de 2015, M. P. Jorge Ignacio Pretelt Chaljub. Sobre la diferencia entre igualdad ante la ley e igualdad en la aplicación de la ley, véase: Juan Carlos Cabañas García. El derecho a la igualdad en la aplicación judicial de la ley. Cizur Menor, Aranzadi, 2010, pp. 51-63. 
de lo contrario, el uso del mismo rasero puede contribuir en la intensificación de esa brecha inicial.

En el ámbito procesal penal, este mandato se materializa de una forma muy específica. El proceso es ante todo un diálogo entre las partes, a través del cual se intenta llegar a la verdad ${ }^{37}$. Para que esa comunicación sea racional, los teóricos de la argumentación jurídica tienen en cuenta una serie de presupuestos esenciales que deben llevarse a cabo, entre los cuales, el principio de igualdad en el debate es sumamente relevante ${ }^{38}$, en especial en dos puntos: (1) igualdad en oportunidades de participación; y (2) la exigencia de que los razonamientos esgrimidos o las conclusiones a las que se llega deben ser aplicables a todos de la misma manera ${ }^{39}$.

Teniendo en cuenta lo anterior, si este proceso comunicativo parte y se mantiene en una posición de desigualdad, realmente no existe un diálogo sino apenas la imposición de una idea sobre otra, dificultando así el acceso a una verdad fiable. Un monopolio de la verdad en manos de las autoridades sólo sería compatible en un Estado autoritario donde no se reconozca ni la libertad ni la dignidad propia de las personas que les faculta para expresar sus opiniones y a que estas sean tenidas en cuenta con igual importancia.

Finalmente, es necesario señalar que las partes en el proceso penal, esto es, fiscalía y defensa, por naturaleza ostentan posiciones abiertamente desiguales donde el primero, por regla general, se ubica en una posición mucho más ventajosa que el segundo, pues, verbigracia, la defensa no dispone de la misma estructura organizacional de la que hace parte el ente acusador. Esta circunstancia debe ser tenida en cuenta a lo largo de todo el proceso, lo cual exige el reconocimiento de especiales facultades para la defensa y la eliminación de todas aquellas medidas que puedan ahondar injustificadamente esa brecha natural de manera que pueda garantizarse, con mayor probabilidad, una igualdad material y no meramente matemática.

\subsection{Concepto de "partes" en el proceso penal}

La igualdad de la que se hablaba en el apartado inmediatamente anterior tiene una naturaleza intrínsecamente relacional, es decir, puede determinarse si existe o no a través de la comparación de una situación en relación con otra. Esos dos extremos entre los que se mide esa igualdad han sido tradicionalmente denominados "partes".

37 Con independencia de toda la discusión sobre el tipo de verdad que se pueda alcanzar. Para los efectos de este texto se entenderá por tal una verdad judicial, aquella que surge del proceso al margen de una concepción ontológica de la misma.

38 Jaime Bernal Cuéllar y Eduardo Montealegre Lynett. El proceso penal, cit., p. 611.

39 Robert Alexy. Teoría de la argumentación jurídica: la teoría del discurso racional como teoría de la fundamentación jurídica. Madrid: Centro de Estudios Constitucionales, 1989. 
Mucho se ha discutido si en un proceso penal puede hablarse en estricto sentido de "partes". Esta discusión se ha dado, principalmente, debido al intento de transposición de categorías propias del proceso civil al procedimiento penal. Quienes argumentan que no puede hablarse de este concepto en el ámbito penal señalan, principalmente, que las partes ejercen derechos propios, con intereses contrapuestos y defienden una posición parcial ${ }^{40}$. En el campo del derecho procesal penal la actividad de la fiscalía se limita únicamente a acusar, por lo que esa carencia de interés imposibilita catalogarle como parte en sentido material. Tampoco puede decirse que el ente persecutor sea absolutamente parcial en la medida en que tiene el deber de buscar pruebas tanto de cargo como de descargo.

En esa línea, arguye la doctrina alemana que el procesado no puede gozar de esa calidad materialmente hablando porque en ocasiones no tiene poder dispositivo y adquiere carácter de medio de prueba ${ }^{41}$. Sería factible hablar de esa noción sólo si se tiene en consideración que le asiste un interés material propio, el cual es, fundamentalmente, la defensa de su libertad y otros derechos que pueden verse afectados con la sentencia.

Así mismo, en la doctrina española se ha negado la existencia de esa categoría desde un enfoque material pues esto implicaría que la relación jurídico-procesal estuviera integrada por quienes participaron en el hecho delictivo, es decir, sujeto activo y sujeto pasivo del mismo, pero puede ocurrir que en la parte activa no esté el ofendido con el delito, sino que sólo actúe la fiscalía, quien iniciará y terminará el proceso sin la presencia de la víctima. Igualmente, puede suceder que, en la posición pasiva, el acusado no sea autor o participe del hecho punible y aun así haya figurado como parte en todo el procedimiento a pesar de no haber tenido participación en el delito ${ }^{42}$.

Por todo lo anterior, autorizada doctrina ${ }^{43}$ ha optado por un concepto formal, en virtud del cual es parte quien postula una resolución judicial frente a otra persona y aquel contra quien se formula dicha resolución ${ }^{44}$, quien ejercita la acción penal y quien la resiste o se opone a ella ${ }^{45}$.

40 Jacobo López Barja de Quiroga. Tratado de Derecho Procesal Penal, 4. a ed. Cizur Menor, Aranzadi, 2010 , p. 619.

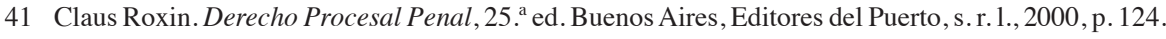

42 Silvia Barona Villar, Juan-Luis Gómez Colomer, Juan Montero Aroca y Alberto Montón Redondo. Derecho jurisdiccional III. Proceso Penal, 18. ${ }^{a}$ ed. Valencia, Tirant lo Blanch, p. 63.

43 Al respecto, véanse los trabajos aquí citados de Jaime Bernal Cuéllar y Eduardo Montealegre Lynett. Véase también Teresa Armenta Deu. Estudios sobre el proceso penal. Buenos Aires, Rubinzal-Culzoni Editores, 2008.

44 Jaime Bernal Cuéllar y Eduardo Montealegre Lynett. El proceso penal, cit., p. 625.

45 Vicente Gimeno Sendra. Derecho Procesal Penal, 2. ed. Cizur Menor, Civitas Thomson Reuters, 2015 , p. 219. 
Ahora bien: aunque esta noción se corresponde principalmente con el juicio oral, debe decirse que el procedimiento también exige en la fase de investigación ${ }^{46}$ la equiparación de las posiciones del investigado y el ente acusador en muchos de sus $\operatorname{contenidos}^{47}$ por lo cual es conveniente hablar de la teoría de la posición jurídica, según la cual hay partes activas y pasivas dependiendo de la situación de un sujeto en la estructura procesal y de los derechos que a este ha asignado la ley. Así, Moreno Catena señala que en la parte activa estaría la fiscalía y el actor civil, mientras que en la parte pasiva se ubica el sospechoso y el civilmente responsable ${ }^{48}$. Este concepto de posición jurídica de las partes se concreta en tres principios, a saber ${ }^{49}$ : (1) la persona sometida a la investigación penal no puede ser tratada como mero objeto del procedimiento sino como un interviniente en él, es decir, no es un simple medio de prueba sino que debe haber un respeto por su dignidad y cuenta con las facultades para participar activamente en el proceso; (2) el fin del proceso penal no es sólo la búsqueda de la verdad sino también proceder respetando las garantías fundamentales; y (3) las desventajas propias de la posición del investigado deben corregirse durante el procedimiento ${ }^{50}$.

Teniendo claro ya el concepto de "parte", debe decirse que en materia de igualdad de armas el oponente no siempre se identifica estrictamente con el acusado o con el fiscal, sino que pueden existir terceros que se unen al proceso, como ha sucedido con el avocat général ${ }^{51}$ o con la figura del amicus curiae ${ }^{52}$, cuyas posiciones u observaciones no pueden predicarse neutrales. En esa línea, señala acertadamente el profesor Kai Ambos que la categorización de las víctimas, hecha por la Sala de Apelaciones de la Corte Penal Internacional y algunos doctrinantes, como participantes y no como partes del procedimiento, es una diferencia más semántica que sustancial, dados sus efectivos derechos de participación ${ }^{53}$.

En ese mismo contexto, hay debate entre quienes consideran que el principio de igualdad de partes debería aplicarse únicamente en favor del acusado, es decir, que la fiscalía no podría alegar ser víctima de una violación a ese mandato ${ }^{54}$; también

46 Donde resultan sumamente relevantes las prohibiciones probatorias con el objetivo de igualar la posición del sospechoso frente a la fiscalía en ese estadio del proceso.

47 Jaime Bernal Cuéllar y Eduardo Montealegre Lynett. El proceso penal, cit., p. 625.

48 Jaime Bernal Cuéllar y Eduardo Montealegre Lynett. El proceso penal, cit., p. 626.

49 Jaime Bernal Cuéllar y Eduardo Montealegre Lynett. El proceso penal, cit., pp. 626-629.

50 Jaime Bernal Cuéllar y Eduardo Montealegre Lynett. El proceso penal, cit., p. 628.

51 Omkar Sidhu. The concept of equality of arms in criminal proceedings under article 6 of the European Convention of Human Rights. Cambridge, Intersentia, 2011, p. 94.

52 Que de facto se ha convertido en abogado defensor. Kai Ambos. Treatise on International Criminal Law, vol. III: International Criminal Procedure. Oxford, Oxford University Press, 2016, pp. 204-205.

53 Kai Ambos. Op. cit., p. 176, nota 733.

54 Omkar Sidhu. Op. cit., p. 112. 
están quienes, como el Tribunal Europeo de Derechos Humanos, arguyen que debe predicarse tanto de la fiscalía como de la defensa y hay otros que, incluso, amplían su aplicación en favor de las víctimas dadas sus especiales facultades de participación dentro del proceso ${ }^{55}$.

Entrar de lleno en esa discusión excede los propósitos de este trabajo; sin embargo, valga hacer una concreta apreciación. Esencialmente el principio de igualdad de armas se orienta a inclinar la balanza en favor del acusado de manera que alcance una condición más cercana a la de la fiscalía, ya que esta goza de una situación mucho más ventajosa. Dada la naturaleza propia de sus roles y posiciones, difícilmente puede presentarse un desequilibro en favor del acusado y a expensas del ente persecutor; no obstante, no existe óbice para que dicha hipótesis pueda tener lugar, por ejemplo, en el proceso penal internacional donde la Corte no tiene la misma fuerza coercitiva que los jueces en el ámbito doméstico, por lo que debe dejarse abierta esa posibilidad con el fin de garantizar el mandato superior de un juicio que como un todo sea justo, pues no debe olvidarse que el ente persecutor actúa, también, en protección de los intereses de las víctimas.

Lo cierto es que la carga de la prueba en ese tipo de casos deberá ser bastante elevada para el órgano acusador ya que, teniendo en cuenta los poderes que posee, su posición es difícilmente afectada y fácilmente reequilibrada a lo largo del procedimiento, incluso sin medidas especiales de contrabalanceo. En cuanto a los demás intervinientes, cuyas opiniones y actuaciones no puedan ser tomadas como neutrales, es necesario decir que la protección de sus prerrogativas debe llevarse a cabo mediante la alegación de una violación a ellas y no bajo el alcance del principio de igualdad de armas debido a que este tiene una finalidad diferente; sin embargo, sus actuaciones pueden ir en apoyo del ente acusador, por lo cual, dado que es un reforzamiento y una voluntad adicional a vencer dentro de la tesis de la fiscalía, sí puede darse un desequilibrio que afecte la igualdad de armas en detrimento de la posición del sospechoso y en favor del ente acusador.

\subsection{Concepto de "armas"}

La idea de "armas" es una noción elemental que responde a la pregunta de cuáles son los mecanismos de ataque y defensa de los que se dispone para cristalizar la disputa entre tesis opuestas; en otras palabras, las facultades para una efectiva presentación del caso.

Desde el punto de vista de la defensa, responde a la pregunta de cómo se defiende o cómo se resiste ante el ejercicio de la acción penal por parte de la fiscalía, lo que en

55 Jaime Bernal Cuéllar y Eduardo Montealegre Lynett. El proceso penal, cit., p. 205. 
lenguaje jurídico-procesal equivale a hablar de garantías y derechos procesales, por lo cual conviene preguntarse ¿cuáles son esos derechos y garantías procedimentales?

Es obligatorio resaltar que no existe un catálogo cerrado debido a que su naturaleza como principio demanda una optimización constante, es cambiante, evolutivo, por lo que señalar con ánimo taxativo su contenido implicaría un cercenamiento que podría poner en peligro la justicia del proceso como un todo. Sin embargo, pueden mencionarse como armas las siguientes facultades: el derecho a recibir información sobre los $\operatorname{cargos}^{56}$ y la evidencia en contra; el acceso a los mecanismos procesales que lo habiliten para confrontar a la fiscalía; el derecho a llamar testigos; comprende también los regímenes de descubrimiento probatorio donde el ente acusador debe enseñar tanto evidencia inculpatoria como exculpatoria; el acceso a medios estructurales que le permitan llevar a cabo su investigación ${ }^{57}$; y disponer de adecuado tiempo y facilidades para preparar su defensa, entre otros.

\section{5. ¿Cuándo se entiende que se vulnera el principio de igualdad de armas? El concepto de "desventaja"}

El Tribunal Europeo de Derechos Humanos, en un correcto entendimiento de la igualdad material y de la desproporción natural propia de las relaciones entre fiscalía y defensa, ha señalado que toda desigualdad necesariamente es desventajosa pero que, no obstante, para encontrar una afectación significativa a la igualdad entre las partes, debe observarse el proceso como un todo ${ }^{58}$ y así poder mostrar si existió o no un real impacto en este principio.

En esa línea, el Tribunal se ha percatado de que existen actos que por sí solos son capaces de generar un desbalance irracional entre las partes y que pueden afectar profundamente el resultado del proceso, pero también hay otros que, a simple vista o individualmente considerados, no generan ninguna disparidad, aunque sumados unos con otros reflejan una abierta desigualdad ${ }^{59}$ que repercute en la justicia del proceso cuando se le observa in toto. Incluso, cuando existe una desventaja sustancial, pero

56 Organización de las Naciones Unidas. Asamblea General. Estatuto de Roma de la Corte Penal Internacional, 17 de julio de 1998 .

57 Amy DiBella y Charles Jalloh. "Equality of Arms in International Criminal Law: Continuing Challenges", en Legal Studies Research Paper Series. Pittsburgh: The Ashgate Research Companion to International Criminal Law - Critical Perspectives, n. ${ }^{\circ}$ 28. September 2013, pp. 251-287, disponible en [https://papers.ssrn.com/sol3/papers.cfm?abstract_id=2314587] (consulta: 7 de julio de 2019).

58 Masha Fedorova. Op. cit., p. 40.

59 Juan José López Ortega. "Prueba y proceso equitativo. Aspectos actuales en la jurisprudencia del Tribunal Europeo de Derechos Humanos", en Revista Derechos y Libertades. Madrid: Universidad Carlos III de Madrid, Instituto Bartolomé de las Casas, Boletín Oficial del Estado, n. 2 2, 1993-1994,pp. 597-628, disponible en [https://e-archivo.uc3m.es/handle/10016/1482] (consulta: 7 de julio de 2019). 
posteriormente se prevén remedios o medidas de contrabalanceo, se ha entendido que el principio de igualdad de armas no se vulnera pues un examen general del procedimiento demuestra que sigue siendo justo.

La influencia de la anterior doctrina ha sido determinante en la jurisprudencia de la CPI, que también ha optado por un análisis del proceso como un todo ${ }^{60}$ para determinar si ha tenido lugar una vulneración a la paridad procesal de las partes y así ha indicado, por ejemplo, que la igualdad de armas no se refiere a una igualdad matemática en recursos, sino que atiende a un concepto de balance.

\section{DEFINICIÓN DEL PRINCIPIO DE IGUALDAD DE ARMAS}

La "compleja categoría de igualdad de armas" 61 , cuya referencia es obligada en todo estudio serio, no solo de procedimiento penal sino de derecho procesal en general ${ }^{62}$, no goza de consenso en cuanto a su definición, contenido y alcance, ni en la doctrina, ni en la jurisprudencia, lo cual trae consigo confusión, desorden y errores conceptuales que dificultan su estudio, entendimiento y aplicabilidad. Específicamente, en el ámbito del derecho procesal penal son varios los fundamentos y definiciones que a tal categoría han sido asignadas, como se verá a continuación.

\subsection{Posiciones sobre su fundamento y definición}

En España, el Tribunal Constitucional ha sido bastante ambiguo y en algunas de sus decisiones ha manifestado que el principio de igualdad de armas es una exigencia del principio de contradicción ${ }^{63}$; en otras ha dicho que se encuentra dentro del derecho a la tutela judicial efectiva ${ }^{64}$; en otras ha afirmado que hace parte del derecho a un proceso con todas las garantías ${ }^{65} \mathrm{y}$ en otras le ha tratado como una consecuencia del derecho de defensa ${ }^{66}$. De la misma forma, autorizada doctrina ${ }^{67}$ le ha caracterizado como una proyección del genérico principio de igualdad que se manifiesta en un proceso con todas las garantías, indicando que se vulnera cuando el legislador crea

60 Al respecto, véase el apartado 3 de este texto.

61 Jaime Bernal Cuéllar y Eduardo Montealegre Lynett. El proceso penal, cit., p. 628.

62 Desde este estudio se plantea la viabilidad del principio de igualdad de armas como un principio general del Derecho.

63 AATC 655 de 1984.

64 SSTC 76/1982, del 14 de diciembre; 161/1985, del 29 de noviembre; 47/1987, del 22 de abril; 180/91, del 23 de septiembre; 162/1993, del 18 de mayo; 51/1996 del 26 de marzo; 77/1997, del 21 de abril; 268/2000 del 13 de noviembre; 221/2003 del 15 de diciembre; 19/2004 del 23 de febrero.

65 SSTC $27 / 1985$ y $14 / 1992$.

66 AATC 783/1985.

67 Vicente Gimeno Sendra. Op. cit., p. 119. 
privilegios procesales sin fundamento constitucional objetivo y razonable o cuando el legislador o el juez crean posibilidades procesales que se niegan a la parte adversa ${ }^{68}$.

En Alemania, donde se le conoce como "Waffengleichheit", en el campo doctrinal se le ha enmarcado dentro del principio general de igualdad de todos los ciudadanos ante la ley ${ }^{69}$, pero también dentro del estudio del fair trial o juicio justo ${ }^{70}$.

En Colombia, la Corte Constitucional ha caracterizado la igualdad de partes como un elemento esencial del principio del juicio justo ${ }^{71}$, aunque también le ha equiparado con la defensa técnica y ha indicado que hace parte del núcleo esencial del derecho a la defensa y al debido proceso ${ }^{72}$. El máximo juez constitucional señaló que dicho principio tiene por objeto "garantizar que el acusador y el acusado tengan a su alcance posibilidades reales y ciertas para ejercer sus derechos y las herramientas necesarias para situarse en un equilibrio de poderes y hacer respetar sus intereses. Este principio supone la existencia de dos partes en disputa y se estructura como un mecanismo de paridad de lucha, de igualdad de trato entre los sujetos procesales o de justicia en el proceso"73.

Desde otra perspectiva, un sector de la doctrina deriva el principio de igualdad de armas del principio de contradicción señalando que el correcto desarrollo del contradictorio supone, necesariamente, la existencia de igualdad de armas entre los contendientes $^{74}$ e indica que "tiene por finalidad subsanar el desequilibrio real que la persecución penal supone para el imputado. Para que sea efectiva requiere no solo rodear al imputado de recursos para incrementar su capacidad defensiva, sino también evitar otorgar facultades a la acusación que signifiquen un nuevo desequilibrio desfavorable para el inculpado" 75 . En esa misma línea, puede encontrarse la opinión de reputada doctrina española que señala que de la dualidad de partes deriva el principio de contradicción cuya garantía depende de que ambos extremos procesales tengan las mismas posibilidades de ataque y defensa ${ }^{76}$.

68 Ibídem.

69 Ibídem.

70 Roxin, C. Op. cit., pp. 79-81.

71 Corte Constitucional de Colombia. Sentencia C-536 del 2008, M. P.: Jaime Araújo Rentería.

72 Corte Constitucional de Colombia. Sentencia C-127 de 2011, M. P.: María Victoria Calle Correa.

73 Corte Constitucional de Colombia. Sentencia C-536 del 2008, M. P.: Jaime Araújo Rentería.

74 Lisi Trejo. "Problemas prácticos del proceso penal a la luz del principio de igualdad de armas como garantía constitucional del imputado", en Revista Aequitas, vol. 9, n. ${ }^{\circ}$ 9. Buenos Aires, Universidad del Salvador, 2015, pp. 287-305, disponible en [https://p3.usal.edu.ar/index.php/aequitas/article/ download/3942/4880] (consulta: 7 de julio de 2019).

75 Ibídem.

76 Lorenzo Bujosa Vadell, Isabel Huertas Martín, Marta del Pozo Pérez y Carmen Vicente Jiménez. Derecho Procesal Penal, 2. ${ }^{a}$ ed. Salamanca, Universidad de Salamanca, 2007, p. 95. 
Por otra parte, como se vio, el Tribunal Europeo de Derechos Humanos lo ha reconocido dentro del mandato general del fair trial consagrado en el artículo 6. ${ }^{\circ}$ del CEDH, señalando que consiste en que "cada parte debe tener una oportunidad razonable para presentar su caso en condiciones que no lo pongan en desventaja con respecto a su oponente" $" 77$.

También la CPI ha encontrado el fundamento de la paridad de partes en el juicio justo $^{78}$ y, así, la Sala de Cuestiones Preliminares ha dicho que se refiere a la capacidad de una parte en un procedimiento para presentar adecuadamente su caso, con miras a influir, en su favor, en el resultado final del mismo ${ }^{79}$. En ese orden de ideas, respecto al contenido de la garantía, otra sala expresó que "una aplicación efectiva y significativa del principio audi alteram partem requiere que la parte demandada tenga suficiente tiempo para preparar su defensa" 80 . Igualmente, otra sala señaló que igualdad de armas, en el sentido de un equilibrio justo entre las partes, se mantiene cuando una parte tiene la oportunidad real de presentar su caso, en condiciones que no la ponen en una desventaja sustancial frente a su oponente, y de ser evaluado y comentar las observaciones y las pruebas presentadas ante la Corte que puedan influir en su decisión ${ }^{81}$.

De lo anterior puede constatarse que existe acuerdo en cuanto a la existencia del principio de igualdad de armas, pero reina gran confusión respecto a su definición, contenido y alcance, por lo que deviene necesaria su diferenciación con otros mandatos, lo que se hará a continuación, pero de manera muy breve debido a que una elaboración exhaustiva de esta distinción excede los límites de esta investigación.

\subsection{El principio de igualdad de armas y el principio acusatorio}

El principio acusatorio, con el objetivo de asegurar imparcialidad, exige la diferenciación entre un órgano instructor y otro juzgador, la división y reparto de roles

77 Tribunal Europeo de Derechos Humanos. Bulut v. Austria, App, n. . 17358/90, 22 de febrero de 1996, par. 47.

78 International Criminal Court. Prosecutor v. Jean-Pierre Bemba Gombo. "Decision on the Prosecutor's Application for Leave to Appeal Pre-Trial Chamber III's Decision on Disclosure". ICC-01/05-01/08. 25 August 2008, par. 14.

79 International Criminal Court. Prosecutor v. Kony et al. "Decision on Prosecutor's application for leave to appeal in part Pre-Trial Chamber II's Decision on the Prosecutor's application for Warrants of Arrest under article 58”. ICC-02/04. 18 July 2005.

80 International Criminal Court. Prosecutor v. Germain Katanga and Ngudjolo Chui. "Decision on the 'Prosecution's Application Concerning Disclosure Pursuant to rules 78 and 79 (4)'”. ICC-01/04-01/07. 14 September 2010, par. 37.

81 International Criminal Court. Prosecutor v. Jean-Pierre Bemba Gombo. "Decision on the Prosecutor's Application for Leave to Appeal Pre-Trial Chamber III's Decision on Disclosure". ICC-01/05-01/08. 25 August 2008, par. 14. 
donde uno es el que acusa y otro el que juzga, funciones que, sin embargo, estarán vinculadas por el principio de congruencia según el cual, no se puede condenar por hechos distintos a los que se acusó (de lo cual se deduce que, necesariamente, el procesado debe tener conocimiento previo de ese acto) ni a sujeto diferente de aquel que fue acusado. Así mismo, prohíbe la reforma en perjuicio cuando el recurrente es apelante único. Su relación con el principio de igualdad de armas es clara, pues, por ejemplo, el conocimiento previo de los hechos por los que se acusa es información esencial que constituye una de las armas con las que cuenta el procesado para el desarrollo de una efectiva estrategia defensiva.

No obstante lo antes indicado, el principio de igualdad de armas, en primer lugar, tiene una naturaleza que no se refiere solo a aspectos estrictamente orgánicos, sino que tiene una esencia dual, es decir, por un lado, puede garantizar derechos de manera autónoma y, por otro, tiene una naturaleza de modo, esto, es, ordena la forma en la cual deben desarrollarse ciertas funciones y prerrogativas. Así, por ejemplo, si no se conoce la acusación, flagrantemente se vulnera tanto el principio acusatorio como el de igualdad de partes en tanto se despoja al sospechoso de una de sus armas, pero no basta tampoco con que exista un conocimiento previo de la acusación, sino que este debe darse en condiciones tales que no sitúen a la defensa en una posición de inferioridad frente a la fiscalía, por lo que deberá concederse esa información con la antelación suficiente, de manera detallada, completa y en lenguaje comprensible.

Además, el principio de igualdad de armas tiene una diferencia de grado con el principio acusatorio pues el primero no se circunscribe únicamente a aspectos de diferenciación de órganos y división de funciones, sino que se proyecta sobre cada aspecto del proceso, verbigracia, guía también la manera en la que las víctimas pueden participar en el procedimiento penal (de manera tal que no se genere un desbalance en perjuicio para el acusado) o las condiciones en las cuales debe ser desarrollada la producción de material probatorio por parte de la defensa.

\subsection{El principio de igualdad de armas y el mandato general de igualdad}

Aunque el mandato general de igualdad guarda una estrecha relación con el principio que aquí se estudia y señala varios de sus aspectos más importantes, debe decirse que no logra explicarlo de manera completa en su concreto ámbito de ejercicio. Su correcto entendimiento deriva, también, de su conexión con el principio acusatorio y de contradicción ${ }^{82}$, pues es a partir de sus interrelaciones como cobra una naturaleza especial y propia, no solo más detallada, sino diferente, por lo que su existencia no podrá predicarse, a pesar de existir un reconocimiento expreso del mandato general de igualdad en sistemas donde no se pueda hablar de partes en contienda.

82 Lisi Trejo. Op. cit., p. 290. 


\subsection{El principio de igualdad de armas y el principio de contradicción}

Estos mandatos gemelos tienen varias características en común; sin embargo, una sutil diferencia ha sido señalada por el Tribunal Europeo de Derechos Humanos, quien ha indicado que el principio de contradicción ordena que ambas partes cuenten con los mismos documentos ${ }^{83}$ en el momento de llevar a cabo las alegaciones, mientras que la igualdad de partes exige que ambos extremos procesales tengan la oportunidad de exponer sus argumentos en un plazo razonable y sin que tenga lugar una situación de desventaja de una parte frente a la otra ${ }^{84}$. Posteriormente, señaló el Tribunal que el principio de igualdad de armas incorpora el derecho a un juicio contradictorio y así, cuando a ambos contendientes les es negada la posibilidad de estudiar información útil, hay vulneración del principio de contradicción, pero no hay transgresión a la igualdad de partes ${ }^{85}$.

Finalmente, cabe decir que el principio de igualdad de armas se diferencia también del principio de contradicción desde una perspectiva de grado o generalidad, pues este último se refiere a muy concretos ámbitos como la presentación del caso, evidencia y alegatos, entre otros, mientras que, como se ha visto, la paridad de partes tiene un alcance mucho más amplio y en actuaciones de variada naturaleza.

\subsection{Sistema procesal dentro del cual se enmarca el principio de igualdad de armas ¿inquisitivo o adversativo? ¿Es útil esta distinción?}

Ya desde hace varios años se viene criticando esa distinción por múltiples y fuertes argumentos que le han tildado de irrelevante, vaga, inconsistente e insulsa ${ }^{86}$, de los cuales vale mencionar el hecho de que no permite caracterizar una estructura de procedimiento específica ${ }^{87}$ pues cada estado adopta un método con base en su tradición jurídica, lo cual ha llevado a que se implementen modelos con características tanto inquisitivas como adversariales ${ }^{88}$, por lo que los principios configuradores de un sistema no dicen nada per se. Por ejemplo, existen modelos acusatorios con

83 Así como también implica el derecho a discutirlos.

84 Tribunal Europeo de Derechos Humanos. Caso Fretté v. Francia. App, n. ${ }^{\circ}$ 36515/1997. Sentencia del 26 de marzo de 2002.

85 Tribunal Europeo de Derechos Humanos. Caso Dima v. Romania. App, n. ${ }^{\circ}$ 58472/00. Sentencia del 11 de noviembre de 2006.

86 Sarah Summers. Fair Trials: The European Criminal Procedural Tradition and the European Court of Human Rights. Oxford, Hart Publishing, 2007, p. 5.

87 Es por eso que han surgido otros intentos por modelar el procedimiento criminal, dentro de los cuales vale mencionar: Herbert Packer. The Limits of the Criminal Sanction. Stanford, Stanford University Press, 1968; Mirjan Damaška. The Faces of Justice and State Authority: A comparative approach to the Legal Process. Connecticut, Yale University Press, 2009.

88 Jaime Bernal Cuéllar y Eduardo Montealegre Lynett. El proceso penal, cit., p. 192. 
jueces profesionales y no con jurados populares o de conciencia ${ }^{89}$. No obstante, varios aportes de la dicotomía primigenia pueden resultar útiles para el estudio de la igualdad de partes.

Tradicionalmente se ha vinculado el principio de igualdad de armas a la existencia de un proceso adversativo ${ }^{90}$. Y es que no podría ser de otra manera, pues en un proceso puramente inquisitivo esa garantía no tendría lugar teniendo en cuenta que no existe como tal una contienda entre los extremos procesales; es más, el acusado no es siquiera considerado parte en el proceso, sino apenas un mero objeto de prueba del cual el juez hace uso con el objetivo de ratificar en fase de juicio la idea que preconcibió mientras realizó la investigación.

Ahora bien: esa división teórica también permitió percatarse de que lo realmente importante es desentrañar los valores que rigen un determinado modelo de manera que un estudio de sus instituciones y de su desarrollo haga posible una evaluación de la coherencia del mismo y así determinar si, en su conjunto, es justo o no de acuerdo con esos valores propios de la cultura jurídica en la cual fue creado. De esta manera, el principio de igualdad de armas tendrá un mayor o menor juego dependiendo de qué valores se privilegian en uno u otro sistema. Verbigracia, en un sistema que prefiera la búsqueda de la verdad sobre el respeto por los derechos del procesado, la igualdad entre las partes tendrá un campo de acción más restringido.

Para concluir, debe decirse que para que pueda ser factible la aplicación del principio de igualdad de armas se requiere la existencia de, al menos, dos partes en el proceso que puedan efectivamente participar en él, lo cual tendrá lugar en todo Estado de derecho, pues es allí donde el respeto por la dignidad del ser humano se hace verdaderamente exigible, lo que imposibilita un tratamiento del procesado como un simple objeto de prueba, donde su actividad en el procedimiento tiene la posibilidad de determinar el resultado del juicio.

\section{CONCLUSIONES}

Primera. El principio de igualdad de armas tiene antecedentes que pueden ser rastreados hasta la antigua Grecia con el establecimiento de la máxima audi alteram partem.

Segunda.Al ser un mandato de optimización, demanda la realización de una igualdad procesal en la mayor medida posible teniendo en cuenta las posibilidades jurídicas y fácticas existentes.

89 Juan Montero Aroca. Principios del proceso penal. Una explicación basada en la razón. Valencia, Tirant lo Blanch, 1997, pp. 25-30.

90 Luigi Ferrajoli. Derecho y Razón. Teoría del garantismo penal, 7. ed. Madrid, Trotta, 2005,pp. 93-94 y 614 . 
Tercera. La igualdad a la que se refiere es material y no matemática. Por lo tanto, debe tener en cuenta la disparidad natural de los contendientes y las especiales calidades de cada uno de ellos.

Cuarta. Esa igualdad se predica de las "partes" del proceso, entendiendo por "parte" a aquella que postula una resolución judicial frente a otra persona o contra quien se formula dicha resolución.

Quinta. Por "armas" debe entenderse todos los mecanismos de ataque y defensa de los que dispone una parte del proceso para cristalizar la disputa entre tesis opuestas; en otras palabras, las condiciones, facultades y oportunidades para una efectiva presentación del caso.

Sexta. El principio de igualdad de armas se vulnera cuando tiene lugar una desventaja sustancial que afecta la justicia del proceso visto como un todo.

Séptima. Existen diferentes posiciones sobre el fundamento, la definición y el alcance del principio de igualdad de armas. Así, por ejemplo, hay quienes lo enmarcan dentro del derecho a la tutela judicial efectiva; otros señalan que es una consecuencia del derecho de defensa o lo asimilan a este; algunos encuentran su fundamento en el fair trial, otros en el mandato general de igualdad, etc.

Octava. Si bien el mandato de igualdad de armas guarda similitudes con el principio acusatorio, se distancia de este en la medida en que no se refiere necesariamente a aspectos orgánicos en sentido estricto, sino que tiene una esencia dual.Así mismo, tiene una diferencia de grado ya que no se circunscribe únicamente a aspectos de diferenciación de órganos y funciones, sino que se proyecta sobre cada aspecto del proceso.

Novena. El principio de igualdad de armas tiene una estrecha relación con el mandato general de igualdad. No obstante, este no logra explicarlo en su integridad ya que la igualdad procesal se explica en razón de su conexión con el principio acusatorio y de contradicción.

Décima. El principio de igualdad de armas se diferencia del principio de contradicción en la medida en que este último exige que ambas partes cuenten con los mismos documentos en el momento de llevar a cabo las alegaciones, mientras que la igualdad de partes exige que ambas partes tengan la oportunidad de exponer sus argumentos en un plazo razonable y sin que tenga lugar una situación de desventaja de una parte frente a la otra. En esa línea, el TEDH también señaló que el principio de igualdad de armas incorpora el derecho a un juicio contradictorio. Igualmente, estos dos principios tienen una diferencia de grado en el entendido de que el principio de contradicción se refiere a ámbitos muy concretos como la presentación del caso, evidencia y alegatos, entre otros, mientras que la paridad de partes tiene un alcance mucho más amplio y en actuaciones de variada naturaleza. 
Undécima. Si bien la distinción entre procesos adversativos e inquisitivos se considera hoy insulsa, es útil para señalar que el principio de igualdad de armas tendrá lugar únicamente allí donde exista un elemento adversarial mínimo que permita una contienda procesal entre dos partes opuestas.

\section{REFERENCIAS}

\section{Doctrina}

Alexy, Robert. Teoría de la argumentación jurídica: la teoría del discurso racional como teoría de la fundamentación jurídica. Madrid, Centro de Estudios Constitucionales, 1989.

Alexy, Robert. Teoría de los derechos fundamentales. Madrid, Centro de Estudios Constitucionales, 1997.

Ambos, Kai. Treatise on International Criminal Law, vol. III: International Criminal Procedure. Oxford, Oxford University Press, 2016.

Andrews, Richard. Law, Magistracy and crime in old regime Paris 1735-1789, vol. 1: The system of criminal justice. Cambridge, Cambridge University Press, 1994.

Armenta Deu, Teresa. Estudios sobre el proceso penal. Buenos Aires, RubinzalCulzoni Editores, 2008.

Barona Villar, Silvia; Juan-Luis Gómez Colomer, Juan Montero Aroca y Alberto Montón Redondo. Derecho jurisdiccional III. Proceso Penal, 18. a ed. Valencia, Tirant lo Blanch.

Bartlett, Robert. Trial by fire and water: The medieval judicial ordeal. Oxford, Clarendon, 1986.

Bernal Cuéllar, Jaime y Eduardo Montealegre Lynett. El proceso penal, t. I: Fundamentos constitucionales y teoría general, 6. ${ }^{\mathrm{a}}$ ed. Bogotá, Universidad Externado de Colombia, 2013.

Bernal Pulido, Carlos. El principio de proporcionalidad y los derechos fundamentales. Madrid, Centro de Estudios Políticos y Constitucionales, 2003.

Blackstone, William. Commentaries on the Law of England, 13. a ed. London, A. Strahan, 1800 .

Bujosa Vadell, Lorenzo; Isabel Huertas Martín, Marta del Pozo Pérez y Carmen Vicente Jiménez. Derecho Procesal Penal, 2. ${ }^{a}$ edición. Salamanca: Universidad de Salamanca, 2007. 
Cabañas García, Juan Carlos. El derecho a la igualdad en la aplicación judicial de la ley. Cizur Menor, Aranzadi, 2010.

Card Bourne, Frank y Paul Robinson Coleman-Norton. Ancient Roman Statutes: a translation with introduction, commentary, glossary and index. Texas, 1961.

Damaška, Mirjan. The Faces of Justice and State Authority: A comparative approach to the Legal Process. Connecticut, Yale University Press, 2009.

DiBella, Amy y Charles Jalloh. "Equality of Arms in International Criminal Law: Continuing Challenges", en Legal Studies Research Paper Series. Pittsburgh: The Ashgate Research Companion to International Criminal Law - Critical Perspectives, n. ${ }^{\circ}$ 28. September 2013, pp. 251-287, disponible en [https://papers.ssrn.com/sol3/ papers.cfm?abstract_id=2314587] (consulta: 7 de julio de 2019).

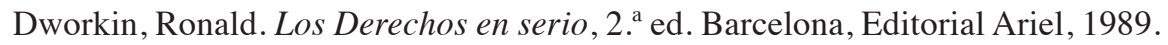

Dworkin, Ronald. “The model of Rules", en The University of Chicago Law Review, vol. 35, Chicago, University of Chicago Law School, 1967, pp. 14-46, disponible en [https://chicagounbound.uchicago.edu/cgi/viewcontent .cgi article $=3553 \&$ context $=$ uclrev] (consulta: 7 de julio de 2019).

Esmein, Adhémar. A History of Continental Criminal Procedure. New Jersey, The Lawbook Exchange, 2000, pp. 90-91.

Fedorova, Masha. The Principle of Equality of Arms in International Criminal Proceedings. Cambridge, Intersentia, 2012.

Ferrajoli, Luigi. Derecho y razón. Teoría del garantismo penal, 7. a ed. Madrid, 2005.

Gimeno Sendra, Vicente. Derecho Procesal Penal, 2. ${ }^{\text {a }}$ ed. Cizur Menor, Civitas Thomson Reuters, 2015.

Lea, Henry Charles. A history of the inquisition of the middle ages. New York, Harper and Brothers, Franklin Square, 1887.

López Barja de Quiroga, Jacobo. Tratado de Derecho Procesal Penal, 4. ${ }^{\text {a ed. Cizur }}$ Menor, Aranzadi, 2010.

López Ortega, Juan José. "Prueba y proceso equitativo. Aspectos actuales en la jurisprudencia del Tribunal Europeo de Derechos Humanos", en Revista Derechos y Libertades. Madrid, Universidad Carlos III de Madrid, Instituto Bartolomé de las Casas, Boletín Oficial del Estado, n. . 2, 1993-1994, pp. 597-628, disponible en [https:/earchivo.uc3m.es/handle/10016/1482] (consulta: 7 de julio de 2019). 
Montero Aroca, Juan. Principios del proceso penal. Una explicación basada en la razón. Valencia, Tirant lo Blanch, 1997.

Organización de las Naciones Unidas. Asamblea General. Estatuto de Roma de la Corte Penal Internacional, 17 de julio de 1998.

Packer, Herbert. The Limits of the Criminal Sanction. Stanford, Stanford University Press, 1968.

Roxin, Claus. Derecho Procesal Penal, 25. ed. Buenos Aires, Editores del Puerto, s. r. 1., 2000.

Sidhu, Omkar. The concept of equality of arms in criminal proceedings under article 6 of the European Convention of Human Rights. Cambridge, Intersentia, 2011.

Summers, Sarah. Fair Trials: The European Criminal Procedural Tradition and the European Court of Human Rights. Oxford: Hart Publishing, 2007.

Trejo, Lisi. "Problemas prácticos del proceso penal a la luz del principio de igualdad de armas como garantía constitucional del imputado", en Revista Aequitas. Buenos Aires, Universidad del Salvador, vol. 9, n. 9, 2015, pp. 287-305, disponible en [https://p3.usal.edu.ar/index.php/aequitas/article/download/3942/4880] (consulta: 7 de julio de 2019).

Watson, Alan (ed.) (tr). The Digest of Justinian, vol. 4. Pennsylvania, University of Pennsylvania Press, 1998.

\section{Jurisprudencia relevante}

Corte Constitucional de Colombia. Sentencia C-536 de 2008, M. P.: Jaime Araújo Rentería.

Corte Constitucional de Colombia. Sentencia C-127 de 2011, M. P.: María Victoria Calle Correa.

Corte Constitucional de Colombia. Sentencia T-036 de 2015, M. P.: Jorge Ignacio Pretelt Chaljub.

España. Tribunal Constitucional (pleno). Sentencia n. ${ }^{\circ}$ 76/1982, del 14 de diciembre.

España. Tribunal Constitucional (pleno). Sentencia n..$^{\circ}$ 161/1985, del 29 de noviembre.

España. Tribunal Constitucional (pleno). Sentencia n..$^{\circ}$ 47/1987, del 22 de abril. 
España. Tribunal Constitucional (pleno). Sentencia n. ${ }^{\circ}$ 180/1991, del 23 de septiembre. España. Tribunal Constitucional (pleno). Sentencia n. ${ }^{\circ}$ 162/1993, del 18 de mayo. España. Tribunal Constitucional (pleno). Sentencia n. ${ }^{o}$ 51/1996, del 26 de marzo. España. Tribunal Constitucional (pleno). Sentencia n. ${ }^{\circ}$ 77/1997, del 21 de abril. España. Tribunal Constitucional (pleno). Sentencia n. ${ }^{\circ}$ 268/2000, del 13 de noviembre. España. Tribunal Constitucional (pleno). Sentencia n. ${ }^{o}$ 221/2003, del 15 de diciembre. España. Tribunal Constitucional (pleno). Sentencia n..$^{\circ}$ 19/2004, del 23 de febrero. España. Tribunal Constitucional (sección segunda). Auto n. ${ }^{\circ} 655$ del 7 de noviembre de 1984.

España. Tribunal Constitucional (sección tercera). Auto n. ${ }^{\circ} 783$ del 13 de noviembre de 1985.

International Criminal Court. Prosecutor v. Germain Katanga and Ngudjolo Chui. "Decision on the 'Prosecution's Application Concerning Disclosure Pursuant to rules 78 and 79 (4)'”. ICC-01/04-01/07. 14 September 2010.

International Criminal Court. Prosecutor v. Jean-Pierre Bemba Gombo. "Decision on the Prosecutor's Application for Leave to Appeal Pre-Trial Chamber III's Decision on Disclosure". ICC-01/05-01/08. 25 August 2008.

International Criminal Court. Prosecutor v. Kony et al. "Decision on Prosecutor's application for leave to appeal in part Pre-Trial Chamber II's Decision on the Prosecutor's application for Warrants of Arrest under article 58". ICC-02/04. 18 July 2005.

Tribunal Europeo de Derechos Humanos. Bulut v. Austria. App, n. ${ }^{o}$ 17358/90, 22 de febrero de 1996.

Tribunal Europeo de Derechos Humanos. Caso Dima v. Romania. App, n. ${ }^{\circ}$ 58472/00. Sentencia del 11 de noviembre de 2006.

Tribunal Europeo de Derechos Humanos. Caso Fretté v. Francia. App, n. ${ }^{\circ}$ 36515/1997. Sentencia del 26 de marzo de 2002. 